\title{
On Cracks and Delaminations of Thermal Barrier Coatings Due to Indentation Testing: Experimental Investigations
}

Jin Yan

University of Delaware

Thorsten Leist

Darmstadt University of Technology

Marion Bartsch

German Aerospace Center

Anette M. Karlsson

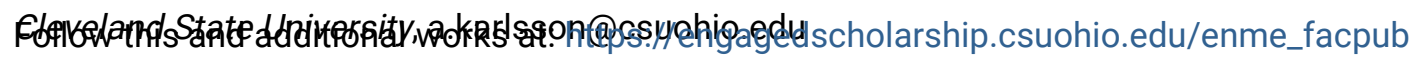

Part of the Mechanical Engineering Commons

How does access to this work benefit you? Let us know!

\section{Publisher's Statement}

NOTICE: this is the author's version of a work that was accepted for publication in Acta Materialia. Changes resulting from the publishing process, such as peer review, editing, corrections, structural formatting, and other quality control mechanisms may not be reflected in this document. Changes may have been made to this work since it was submitted for publication. A definitive version was subsequently published in Acta Materialia, 56, 15, (09-01-2008); 10.1016/j.actamat.2008.04.039

\section{Original Citation}

Yan, J., Leist, T., Bartsch, M., 2008, "On Cracks and Delaminations of Thermal Barrier Coatings due to Indentation Testing: Experimental Investigations," Acta Materialia, 56(15) pp. 4080-4090.

This Article is brought to you for free and open access by the Mechanical Engineering Department at EngagedScholarship@CSU. It has been accepted for inclusion in Mechanical Engineering Faculty Publications by an authorized administrator of EngagedScholarship@CSU. For more information, please contact library.es@csuohio.edu. 


\title{
On cracks and delaminations of thermal barrier coatings due to indentation testing: Experimental investigations
}

\author{
Jin Yan ${ }^{\mathrm{a}}$, Thorsten Leist ${ }^{\mathrm{b}}$, Marion Bartsch ${ }^{\mathrm{c}}$, Anette M. Karlsson ${ }^{\mathrm{a}, *}$ \\ ${ }^{a}$ Department of Mechanical Engineering, University of Delaware, Newark, DE 19716, USA \\ ${ }^{\mathrm{b}}$ Darmstadt University of Technology, Materials Science, NAW, 64287 Darmstadt, Germany \\ 'Institute of Materials Research, German Aerospace Center (DLR), Linder Hoehe, D-51147 Cologne, Germany
}

\section{Introduction}

Thermal barrier coatings (TBCs) are used in a range of industrial applications, e.g. on cooled gas turbine blades or vanes, in order to reduce the temperature of these parts. Unfortunately, design engineers are not able to take full advantage of TBCs since reliable lifetime assessment methods for the coating system are not available. Even though significant efforts have been dedicated towards improving the reliability of TBCs, the failures are not completely understood. The lack of understanding of the failures in TBCs stems from the complex structure of the coatings. A TBC is a multilayered system, where an aluminum-rich metallic bond coat is deposited on the superalloy, followed by a ceramic top coat deposited on the bond coat. During processing and further thermal exposure, a third layer is

\footnotetext{
- Corresponding author. Tel.: +1 302831 6437; fax: +1 3028313619.
} E-mail address: karlsson@udel.edu (A.M. Karlsson). formed between the bond coat and the top coat. This layer is commonly referred to as the thermally grown oxide (TGO), primarily made up by alumina $\left(\mathrm{Al}_{2} \mathrm{O}_{3}\right)$. Yttria-stabilized zirconia (YSZ) is currently the most commonly used top coat material. The ceramic top coat is by design porous, to allow for strain tolerance during thermal cycling, thereby preventing instantaneous spallation. Two major groups of bond coat have emerged: platinum aluminide and MCrAlY $(\mathrm{M}=\mathrm{Fe}$ or NiCo). The in-service failures of the coating systems occur in most cases by debonding (delamination) of the coating, followed by subsequent spallation. The delamination is normally associated with the TGO $[1,2]$. The cracks are not necessarily seen at one particular interface but may occur at the interface between either the top coat and TGO, or the bond coat and TGO, and may even occur as cohesive failure in one of the layers. The failure process is highly sensitive to the system parameters such as processing technique and pattern of use (e.g. power generation vs. propulsion). In addition, the thermal 
and mechanical loading changes the microstructure and properties of the materials of the TBC (e.g. [3]).

Several authors have proposed using the (apparent) interfacial fracture toughness to describe the damage accumulation before spallation [4-7] and - if the fracture toughness can be determined as a function of loading history - as a universal damage parameter in life prediction models [8]. Due to the complex structure of TBCs, establishing the interfacial fracture toughness is a highly challenging task, and an effective method for determining such a property has still not been established. However, several methods have been investigated and proposed. These include utilizing the "pull-out technique" that is traditionally used to study fibers in reinforced ceramics or metals [9], four-point bend testing with a notched coating that initiates the delamination [10], and indentation techniques [5,11-13]. The indentation technique shows great promise, since it requires only minimum sample preparation along with small quantities of material and is easy to perform. However, a major drawback is the difficulty of interpreting the test results; it is this interpretation that has motivated the present work.

The basic premise for using the indentation technique to measure interfacial fracture toughness is based on the notion that the indenter penetrates the coating and generates plastic and elastic deformations in the system, driving cracks in the interface between the coating and substrate. A general technique to evaluate this was proposed by Drory and Hutchinson [14], who analyzed the indentation of a coating with indentation perpendicular to the interface using a Rockwell Brale C (conical) indenter. They showed that with increasing indentation depth, the delamination between a thin film and a substrate increases, and that the diameter of the delamination can be linked to the interfacial fracture toughness. Based on this work, Vasinonta and Beuth [5] investigated the interfacial fracture toughness of TBCs formed by electron beam physical vapor deposition (EB-PVD). In their method, the interfacial fracture toughness is estimated from the calculated in-plane (radial) deformation of the substrate; the measured radii of both the remaining indentation and the debonding crack; the thickness and elastic properties of the coating and thermally grown oxide layers; and the residual stresses in the coating. As an alternative to conical indentation, indentation based on a wedge-shaped indenter has been proposed [12]. Most approaches utilizing indentation testing as a means of measuring interfacial fracture toughness of TBCs focus on flat specimens, but cylindrical specimens have also been considered [11].

Even though the technique proposed to evaluate the interfacial fracture toughness of TBCs shows great promise, some problems appeared when evaluating TBCs with thicker ceramic top coats and TBCs that have been subjected to thermal aging [13]. An earlier experimental study [13] indicated that the technique developed in Ref. [5] predicts that a TBC that has been subjected to extended times at elevated temperatures would have higher interfacial frac- ture toughness than as-processed samples [13]. This contradicts the common understanding of the degradation of TBCs. We believe that the anomalous results in Ref. [13] are due to the role of the microstructural response of the top coat, which included crushing and cracking in the top coat. We note that the system investigated by Bartsch et al. [13] had a thicker top coat than was investigated in

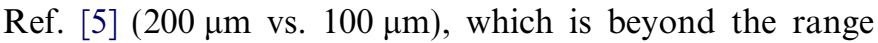
for what Ref. [5] is valid for. Since the technique of evaluating the interfacial fracture toughness was based on a technique developed for thin films [14], extension of the method to thicker top coats (commonly used in industrial applications) might not be possible. To the knowledge of the authors, all the work available in the open literature evaluating interfacial fracture toughness of layered materials such as TBCs neglects the interaction between a porous top coat and the indenter during the indentation process (such as crushing of the porous microstructure). Thus, in this study we aim to investigate the response of the microstructure during indentation.

We will use the Rockwell Brale $\mathrm{C}$ indentation test of a TBC system subjected to a range of thermal histories. Since previous experimental results suggest an important interaction between the indenter and the top coat on the size of debonding cracks $[13,15]$, we will in this paper focus on the micromechanical response of the ceramic top coat, including crushing and formation of cracks. In a companion paper, we conduct numerical simulations to elucidate the response seen from the experimental results presented here [16].

\section{Materials and methods}

\subsection{Specimens}

Rockwell indentation tests were performed on flat specimens comprising a $4 \mathrm{~mm}$ thick, $100 \mathrm{~mm}$ long and $10 \mathrm{~mm}$ wide, isotropic IN 625 substrate, a metallic bond coat, and a ceramic top coat. The substrate was first coated with a $100 \mu \mathrm{m}$ NiCoCrAlY bond coat by EB-PVD and subsequently with a $280 \mu \mathrm{m}$ thick zirconia layer, partially stabilized with 7-8 wt.\% yttria (YSZ), also through EB-PVD. The material system was investigated in the "as-coated" condition and after thermal aging for 50, 100, 200 and $400 \mathrm{~h}$ at $1000^{\circ} \mathrm{C}$ in (laboratory) air. During aging, the samples were kept at high temperature for $23 \mathrm{~h}$ and then cooled to room temperature for $1 \mathrm{~h}$. This cycle was repeated until the desired "time-at-temperature" was reached.

\subsection{Indentation testing}

The surface of the specimens was indented with a Rockwell Brale $\mathrm{C}$ indenter, using an electromechanical testing machine. The displacement of the indenter was recorded by an inductive displacement encoder; the force was recorded with a load cell. The assembly is illustrated in Fig. 1, which also shows the typical force-displacement responses. 

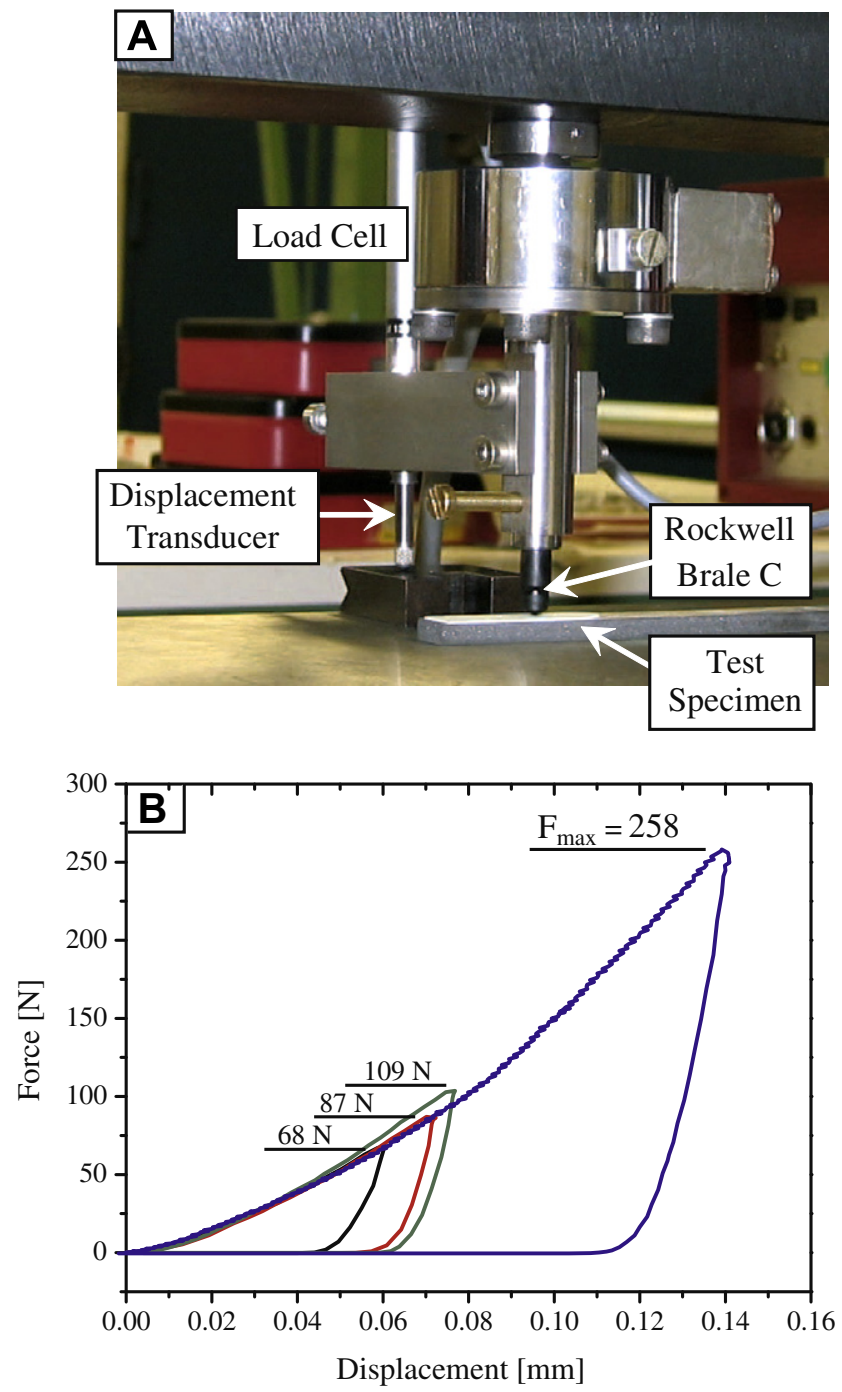

Fig. 1. (A) Test set up for instrumented Rockwell Brale $\mathrm{C}$ indentation. (B) Typical force displacement response for samples aged $50 \mathrm{~h}$ at $1000^{\circ} \mathrm{C}$ in air.
The indentation force was limited to maximum of $3000 \mathrm{~N}$ by the strength of the indenter cone. Since the indentation force was manually controlled, the preselected maximum forces were not exactly reached. The test matrix, listing thermal aging and maximum load in the indentation tests, is shown in Table 1. Several indentations could be made on each specimen. The indentations were made at least $10 \mathrm{~mm}$ away from each other, to avoid interference of the strain fields generated by multiple indentations.

\subsection{Thermography}

Experiments utilizing thermography were employed to investigate when the debonding crack propagates during the loading sequence. In this test, a thermographic camera detects radiation in the infrared range of the electromagnetic spectrum (roughly $0.9-10 \mu \mathrm{m}$ ) and produces images of that radiation. To detect a delamination, a transient temperature difference between delaminated and adherent coating is generated by heating the specimen. The temperature differences are caused by the increased thermal resistivity of the delamination crack with respect to the adherent $\mathrm{TBC}$, resulting in higher temperatures in the TBC above the delamination crack. In our test setup, an AGEMA Thermovision 900 imaging system was used to capture the images. This system is based on the lock-in technique, which uses modulated or cyclic heating. The depth of the temperature sensing can be controlled by the frequency of the modulation of the heat source. Consequently, the quality of the thermographic image in terms of spatial resolution can be optimized. A fan heater, which heated the ceramic surface, was used as the heat source. The modulation frequency was $0.125 \mathrm{~Hz}$, and the achieved spatial resolution was about $0.1 \mathrm{~mm}$. The temperature resolution is $0.1 \mathrm{~K}$, the accuracy is $\pm 1 \mathrm{~K}$, and the frame range is $240 \times 128$ pixels.

In order to avoid reflection from the indenter, the Rockwell indenter was painted black. The experiments were conducted on coated single-crystal CMSX-4 substrate.

Table 1

Test matrix summarizing thermal aging, indentation force and measured crack length parallel to the interface between TBC and bond coat

\begin{tabular}{|c|c|c|c|c|c|c|c|c|c|c|c|}
\hline $\begin{array}{l}\text { Thermal } \\
\text { aging (h at } \\
\left.1000^{\circ} \mathrm{C}\right)\end{array}$ & $\begin{array}{l}\text { Indentation } \\
\text { force }(\mathrm{N})\end{array}$ & $\begin{array}{l}\text { Crack } \\
\text { length } \\
(\mu \mathrm{m})\end{array}$ & $\begin{array}{l}\text { Thermal } \\
\text { aging }(\mathrm{h} \text { at } \\
\left.1000^{\circ} \mathrm{C}\right)\end{array}$ & $\begin{array}{l}\text { Indentation } \\
\text { force }(\mathrm{N})\end{array}$ & $\begin{array}{l}\text { Crack } \\
\text { length } \\
(\mu \mathrm{m})\end{array}$ & $\begin{array}{l}\text { Thermal } \\
\text { aging (h at } \\
\left.1000^{\circ} \mathrm{C}\right)\end{array}$ & $\begin{array}{l}\text { Indentation } \\
\text { force }(\mathrm{N})\end{array}$ & $\begin{array}{l}\text { Crack } \\
\text { length } \\
(\mu \mathrm{m})\end{array}$ & $\begin{array}{l}\text { Thermal } \\
\text { aging }(\mathrm{h} \text { at } \\
\left.1000^{\circ} \mathrm{C}\right)\end{array}$ & $\begin{array}{l}\text { Indentation } \\
\text { force }(\mathrm{N})\end{array}$ & $\begin{array}{l}\text { Crack } \\
\text { length } \\
(\mu \mathrm{m})\end{array}$ \\
\hline 0 & 47.4 & 0 & 50 & 65.4 & 0 & 100 & 49.6 & 0 & 200 & 60.1 & $-{ }^{\mathrm{a}}$ \\
\hline 0 & 61.1 & 0 & 50 & 84.0 & 410.6 & 100 & 73.9 & 338.1 & 200 & 78.6 & $-{ }^{\mathrm{a}}$ \\
\hline 0 & 70.9 & 723.5 & 50 & 96.5 & 608.3 & 100 & 87.1 & 615.6 & 200 & 130.9 & $-^{\mathrm{a}}$ \\
\hline 0 & 82.0 & 847.6 & 50 & 104.9 & 688.0 & 100 & 106.3 & 848.8 & 200 & 227.7 & $-^{\mathrm{a}}$ \\
\hline 0 & 113.4 & 1688.7 & 50 & 268.9 & 1071.7 & & & & & & \\
\hline 0 & 153.1 & 2827.7 & 50 & 559.2 & 1382.0 & & & & 400 & 0 & $-{ }^{\mathrm{b}}$ \\
\hline 0 & 240.2 & 1254.1 & 50 & 967.3 & 3337.7 & & & & 400 & 0 & $-{ }^{\mathrm{b}}$ \\
\hline 0 & 432.4 & 2475.3 & & & & & & & & & \\
\hline 0 & 618.5 & 3663.6 & & & & & & & & & \\
\hline
\end{tabular}

a Delayed, spontaneous spallation, "desktop effect" of the ceramic top coat after indentation.

${ }^{\mathrm{b}}$ Spontaneous spallation of the ceramic top coat after thermal aging. 
This substrate has higher strength than the IN 625 and was selected to ensure sufficiently large indentation loads and consequently delaminations that are large enough to be detectable by thermography. The TBC samples were heated to a few degrees above room temperature during the indentation process. When the delamination develops between the TBC and the substrate, the camera detects the subsequent temperature difference. The method was only used for the larger indentation load, to ensure detectable size of the debonded area.

\subsection{Sample preparation for microscopy}

After the indentations were performed, cross-sections to image the damages and crack patterns associated with the imprint of the indenter were prepared and investigated by optical microscopy and scanning electron microscopy (SEM; LEO Gemini DSM 982 equipped with a field emission gun). Since the image analysis is a key part of this work, explaining the micromechanical response of the TBC during indentation, careful sample preparation was extremely important, and thus the preparation details will be outlined below.

Before metallographic preparation, the crack pattern induced by the indentation in the TBC was fixed by infiltrating the TBC with a mixture of resin and hardener of low viscosity, which was cured at ambient temperature for 1-2 days. Afterwards, the specimens were cut with a $0.5 \mathrm{~mm}$ thick diamond-coated wire. Before embedding the specimens in an electrically conductive epoxy-carbon mixture, the distance between the cut and the indentation center was measured, in order to facilitate the exact preparation of the imprint center. The mounted specimen was hand ground, using abrasive $\mathrm{SiC}$ paper from 200 to 4000 grit, followed by diamond spray with particle size of about $3 \mu \mathrm{m}$. Between the grinding steps, the thickness of the mounted specimen was measured. When approaching the imprint center, an optical microscope was utilized to measure the diameter of the imprint to establish the center of the indentation. The final polishing was performed with $\mathrm{SiO}_{2}$ polishing suspension followed by intensive cleaning with water. Before final imaging in the SEM, each specimen was ion-beam etched for $40 \mathrm{~min}$ and coated with a thin gold film by sputtering for $10 \mathrm{~s}$ with a Gatan High Resolution Ionbeam Coater Model 681 with auxiliary equipment for etching.

The indentation tests generated debonding cracks parallel to the interface between the TGO and top coat. The diameter of each debonding crack was estimated from the length of their projection, which is visible in the cross-sections. SEM was used to measure the crack diameters.

\section{Results}

\subsection{Thermography}

About 2-3 min are needed to produce a thermal image in the thermography test. Thus, during the tests including thermography, the indentation process was temporarily stopped at 1200, 1500, 2000 and $2400 \mathrm{~N}$ (keeping the force constant) during loading, and at $1200 \mathrm{~N}$ during unloading to produce an image. One image was also produced after complete unloading. In all cases, the camera was kept at the same position (not moved).

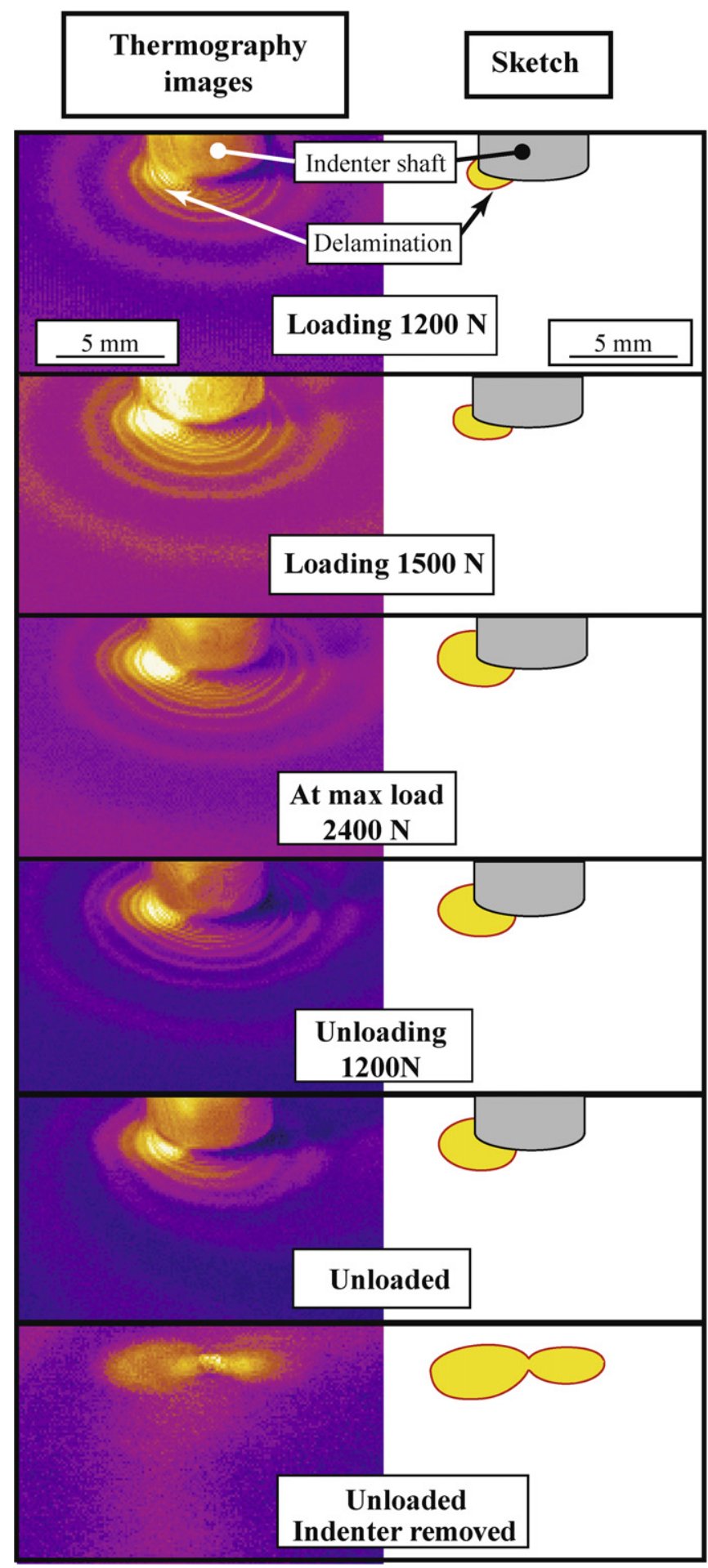

Fig. 2. Images from the thermography (left column) and an interpreted sketch showing the estimated evolution of the delamination (right column). The indenter tip is not visible, only the shaft. 
Sample results from the thermography test are shown in Fig. 2, with a sequence of images showing the response during loading up to the maximum indentation load of $2.4 \mathrm{kN}$ followed by unloading. Based on the images obtained from the thermography (left column in Fig. 2 ), we can estimate the delamination size. We note that the delamination does not grow during unloading, and that a butterfly-shaped delamination is obtained once the indenter is removed. This shape has been associated with the anisotropic substrate [15] that was exclusively used for this set of experiments with thermographic imaging.
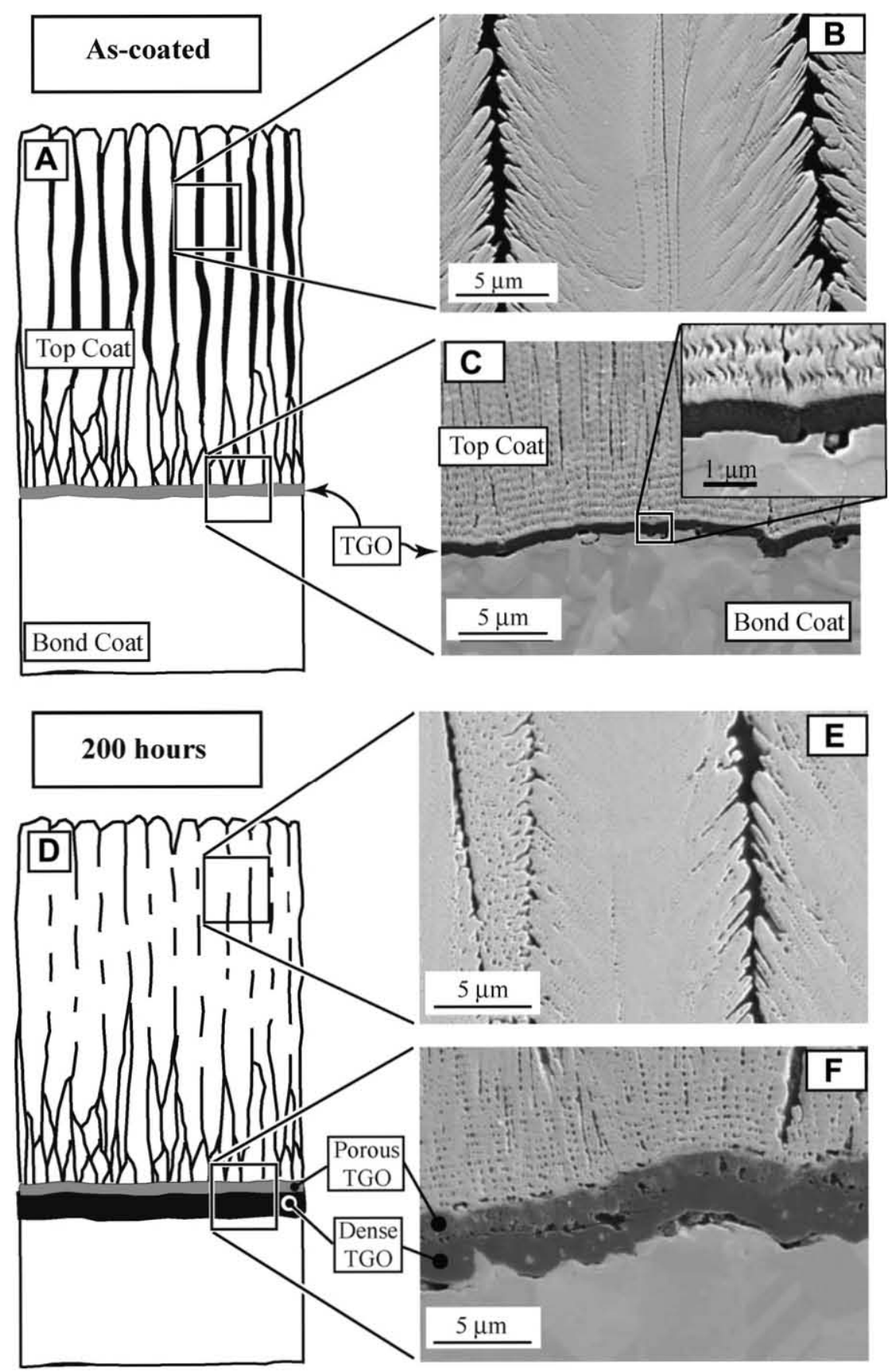

Fig. 3. Microstructural evolution of the TBC system due to thermal aging. For the as-coated system: (A) schematic illustrating gaps between columns along with a thin TGO; (B) micrograph of a near-surface region; and (C) micrograph of the interfacial region where the enlargement indicates a multiphase assembly in the TGO [16]. For the aged samples: (D) schematic illustrating narrowed gaps and rigid interconnections between the top coat columns due to sintering, and a two-layered TGO; (E) micrograph of a near-surface region after $200 \mathrm{~h}$ aging in air, and (F) SEM image of the TGO after $200 \mathrm{~h}$ aging at $1000{ }^{\circ} \mathrm{C}$ in air, showing two distinct layers: a porous layer adjacent to the top coat and a dense layer adjacent to the bond coat. At the interface between layers, a line of fine pores is visible. 


\subsection{Microstructural evolution due to aging}

The TBC displays significant changes in the microstructure due to thermal aging in air. The most dominant changes are sintering of the YSZ top coat with columns sintering together [17], changes in the shape of intracolumnar pores [18] and growth of the TGO [19]. Schematics and representative SEM images illustrating the microstructural evolution due to thermal aging are shown in Fig. 3. Apparent sintering of the top coat results in a reduction of the free surface of the microstructure, by coarsening of the pores and the featherlike side branches of the top coat columns, as well as formation of rigid contacts between columns (Fig. 3). The TGO in the as-coated sample is about $0.6 \mu \mathrm{m}$ thick and is a mixture of alumina with zirconia [19]. During thermal aging, the TGO thickens and develops two distinguishable layers: an alumina layer adjacent to the bond coat and an intermixed zone between the alumina and zirconia (Fig. 3D,F). The intermixed zone is porous, whereas the alumina layer appears dense. Between the intermixed zone and the dense alumina layer, a line of pores is observed (Fig. 3F). This evolution of the microstructure is expected to influence the failure mechanism of the TBC and consequently the response due to indentation.

Delayed separation between the TGO and bond coat occurred several days after the indentation tests (sometimes referred to as the "desk top effect") for specimens aged for $200 \mathrm{~h}$. Specimen that had been aged $400 \mathrm{~h}$ showed spontaneous separation of the ceramic coating after removal from the furnace and were not tested by Rockwell indentation.

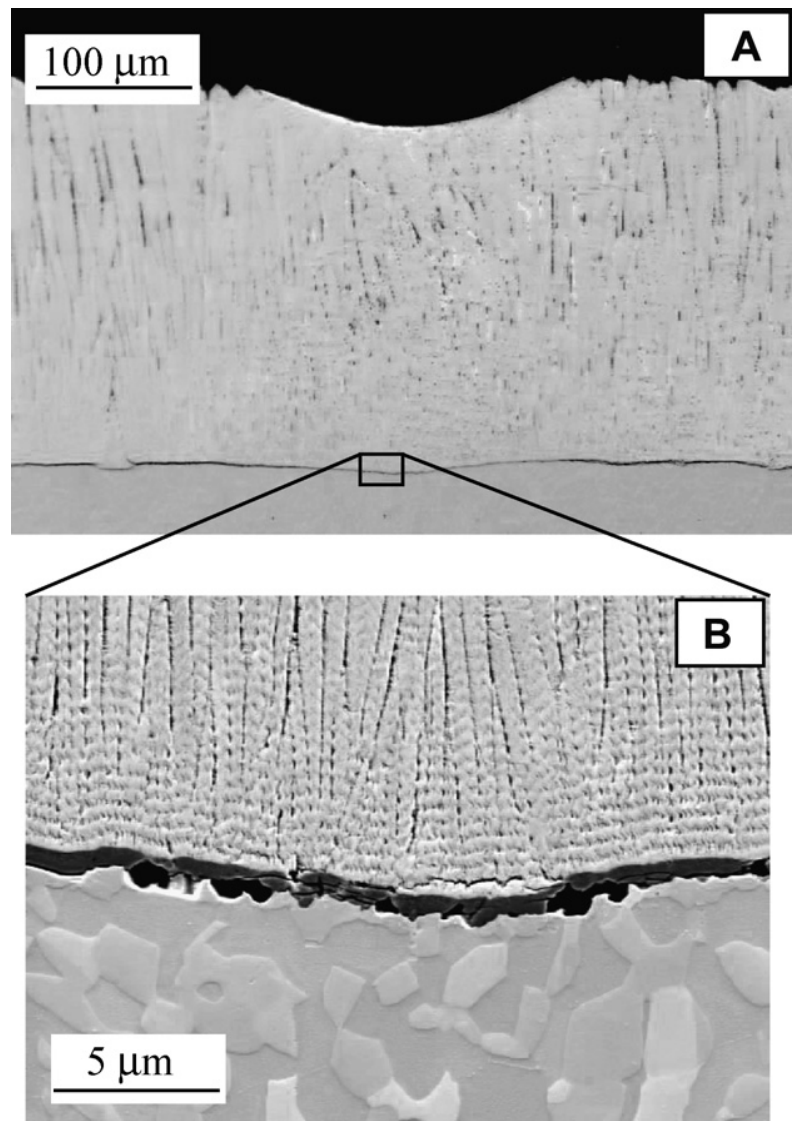

Fig. 5. Cross-section of the TBC in as-coated condition after indentation with indentation force $71 \mathrm{~N}$ : (A) overview and (B) enlargement of the debonding crack under the indent ("center crack").

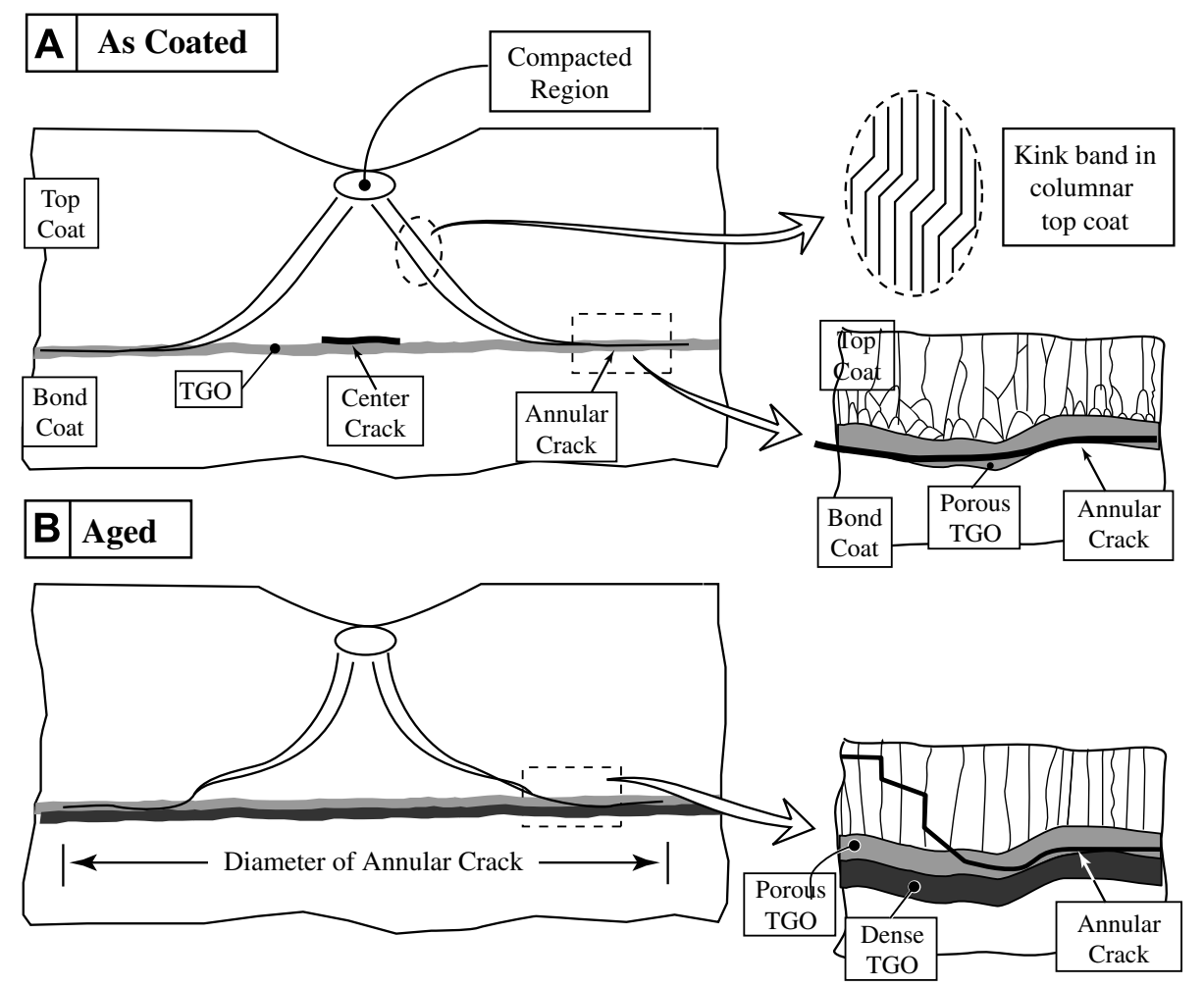

Fig. 4. Schematics summarizing the main crack patterns observed in: (A) as-coated and (B) thermally aged specimens. 


\subsection{Indentation-induced damage}

The Rockwell indentation resulted in various damage features and crack patterns depending on the maximum indentation load and the time-at-temperature that the sample had been subjected to prior to testing. A schematic of the response is shown in Fig. 4, indicating the response for "as-coated" and "aged" samples. Major classes of damage due to indentation are observed, including crushing of top coat adjacent to the indenter tip, cone-shaped shear bands and interfacial cracks.

Directly under the indenter, crushing of the porous top coat is observed (Figs. 5 and 6). This is followed by bending, buckling and finally breaking of the top coat columns. For indentation with maximum indentation force of about $80 \mathrm{~N}$ or more, the top coat typically displays one or multiple conical shear bands, which appear in the two-dimensional cross-sections as two (more or less) symmetric shear bands, spreading approximately at a $45^{\circ}$ angle towards the interface (Figs. 6 and 7). Similar shear bands have been observed upon indentation with a spherical indenter at high temperature [20], and in coatings on airfoils after foreign object damage [21] and erosion [22]. The shear bands appeared clearer and straighter in the as-coated TBC system than in the aged specimens (for the same maximum indentation force). Close to the interface between the top coat and bond coat, the shear cracks deviate and propagate parallel to this interface as annular debonding cracks. Even though indentation with small loads seems on casual investigation to influence only a region around the indentation itself (Fig. 5), careful SEM analyses show delamination cracks under the indentation imprint for the as-coated specimen (Fig. 5). This crack typically connects with the annular debonding crack. At the highest loads tested (maximum indentation force larger

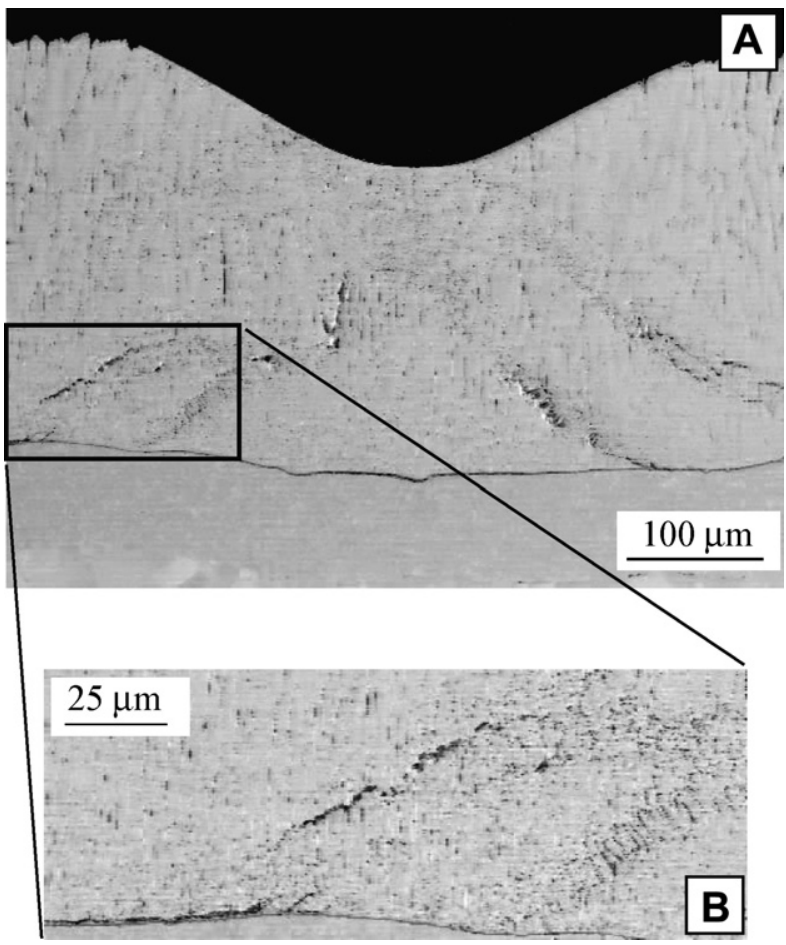

Fig. 7. Cross-section of the TBC in as-coated condition after indentation with indentation force $240 \mathrm{~N}$ : (A) overview with conical shear crack; (B) enlarged view of shear bands near the interface.

than $200 \mathrm{~N}$ ), the substrate and bond coat yields, resulting in an overall deformation of the bond coat (Fig. 8), with a large zone where the interface between the bond coat, TGO and top coat is displaced. Thus, for these loads, the indentation not only imprints the top coat but also significantly affects the bond coat. This was evidently caused by the yield strength of the bond coat and even the substrate being reached for these loads.

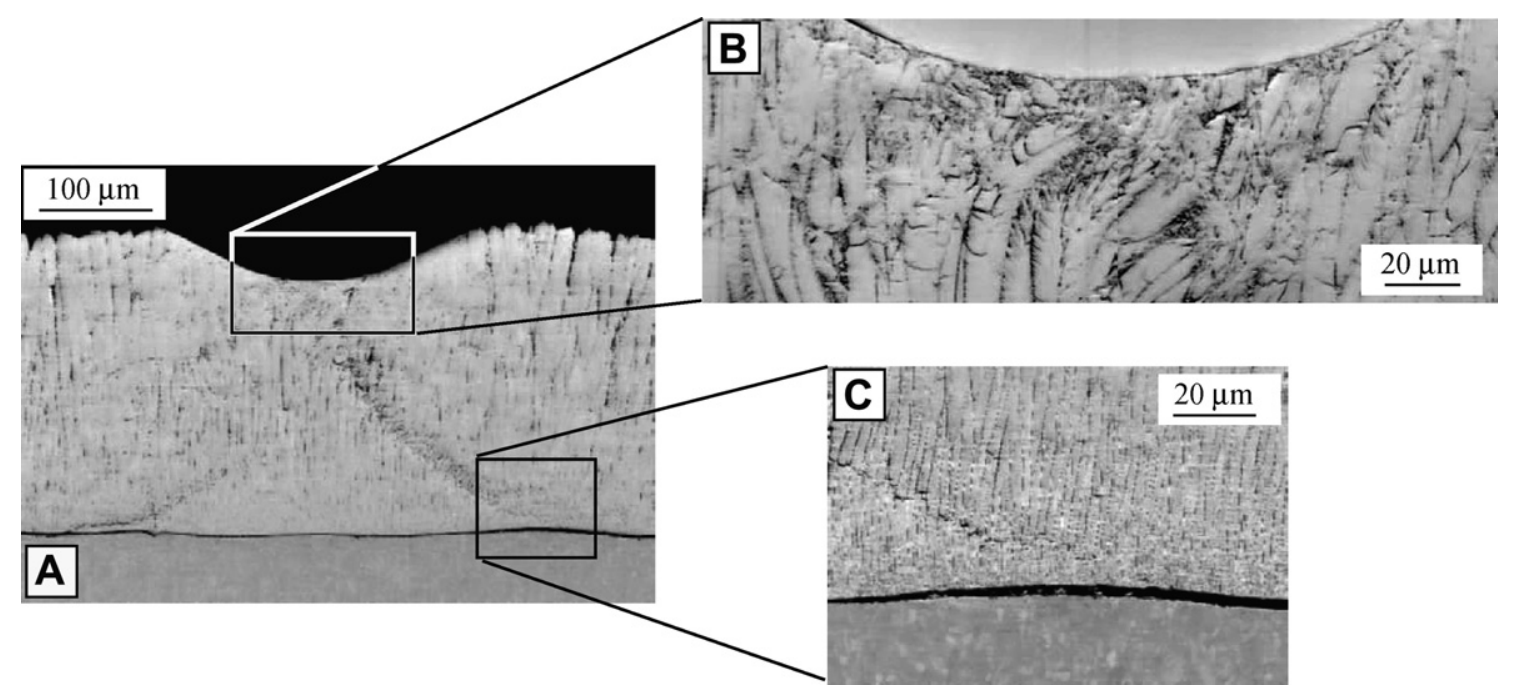

Fig. 6. Cross-section of the TBC in as-coated condition after indentation with an indentation force of $102 \mathrm{~N}$ : (A) overview with conical shear crack; (B) enlarged view of the area underneath the imprint; and (C) enlarged view of annular debonding crack. 


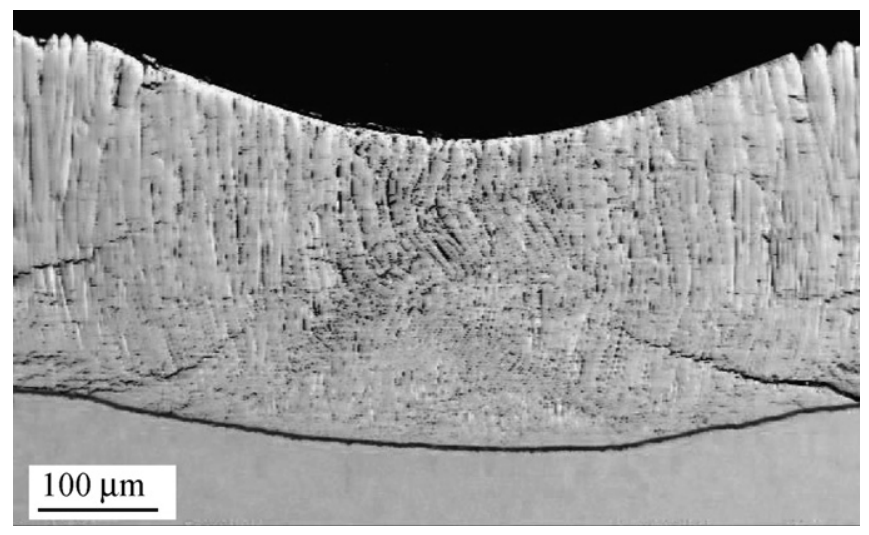

Fig. 8. Cross-section of the TBC after indentation with a maximum indentation force of $610 \mathrm{~N}$, for a system aged for $100 \mathrm{~h}$ at $1000^{\circ} \mathrm{C}$ in air.

\subsection{Debonding cracks}

SEM was used to measure the diameters of the debonding cracks. The crack diameter was defined as the distance between the right and the left end of the annular debonding cracks. This is the outer diameter of the annular debonding cracks if the cross-section is made exactly at the center of the indent. In Fig. 9, the crack diameter of the annular debonding cracks is displayed as a function of the indentation force for samples treated at various times at $1000{ }^{\circ} \mathrm{C}$ in air and for as-coated samples. Some scatter is seen in the data, but the general trend suggests that the as-coated systems give larger debonding cracks than the aged samples (for the same maximum indentation force). It is not possible to differentiate the results for the aged samples, so these

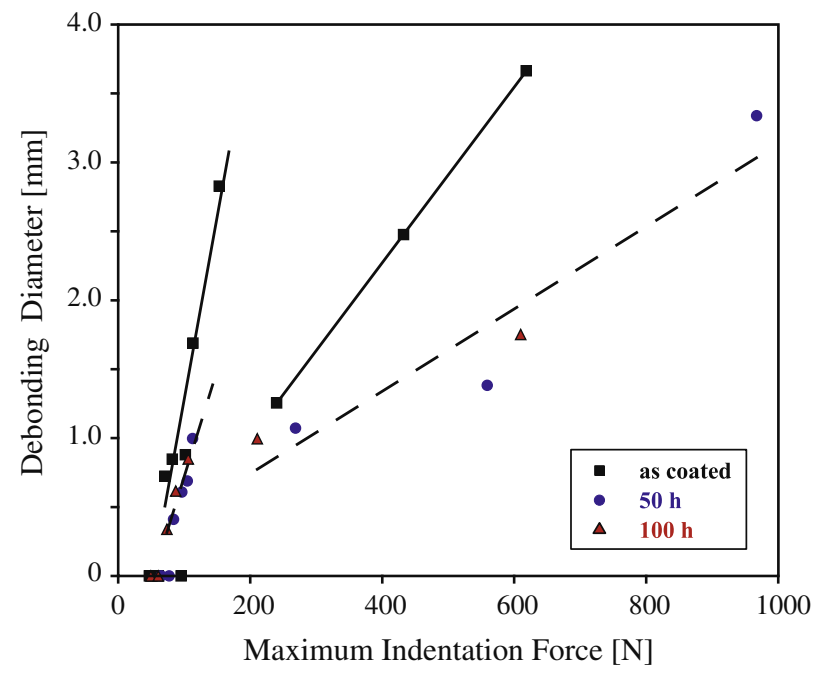

Fig. 9. The diameter of the annular debonding cracks as a function of the indentation force and time-at-temperature. Linear regressions for ascoated samples are shown with solid lines and for aged samples with dashed lines (there is no statistical difference between 50 and $100 \mathrm{~h}$ samples). The debonding diameter shows two distinct responses: one for small maximum indentation forces and one for larger maximum indentation forces, with a bifurcation around $175 \mathrm{~N}$. (The diameter is measured after unloading). are approximated with the same linear response in Fig. 9 (dashed lines). This implies that that the interfacial toughness increases as the system ages and is at variance to the common understanding of the evolution of material properties of TBCs $[8,23,24]$. Moreover, it appears as the response can be divided into two cases: "small" and "large" maximum indentation force. The bifurcation in the response occurs around $175 \mathrm{~N}$. This curious behavior is discussed in a companion paper, where the indentation is investigated through numerical simulations, and it is seen that the bifurcation between "small" and "large" indentation load is associated with the columnar structure [16].

The debonding path along the interface of the top and bond coats depends on the time-at-temperature and is influenced by local microstructural features. The cracks propagated along three possible paths: (i) at the interface between the TGO and bond coat; (ii) within the TGO; and (iii) within the top coat, near to the interface between the top coat and the TGO. The proportion of crack paths along the TGO-bond coat interface, within the TGO, and within the top coat, was estimated and is summarized in Fig. 10. Some typical crack paths in as-coated specimens are depicted in Figs. 11 and 12. Thus, the debonding cracks change with thermal aging from propagating predominantly in the interface between bond coat and TGO towards propagating in the top coat.

\section{Discussion}

The Rockwell Brale $\mathrm{C}$ indentation tests on superalloy samples coated with a TBC, perpendicular to the surface of the top coat, result in complex crack systems that generate annular debonding cracks parallel to the interface between the TGO and the top coat along with cone-shaped shear bands originating at the compacted zone directly under the contact of the top coat with the indenter. These features are summarized in Fig. 4. The shear bands are usu-

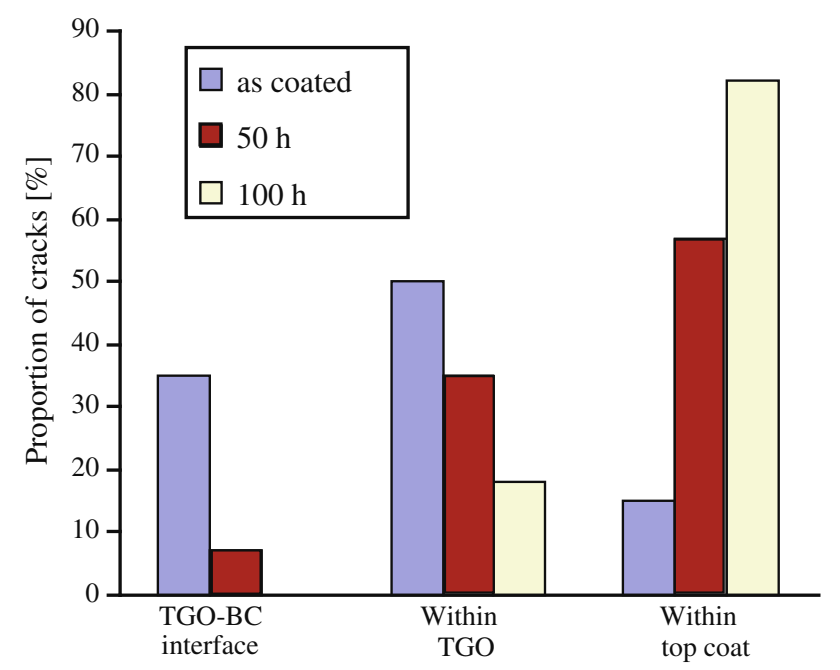

Fig. 10. The proportion of observed crack paths for various time-attemperature. 

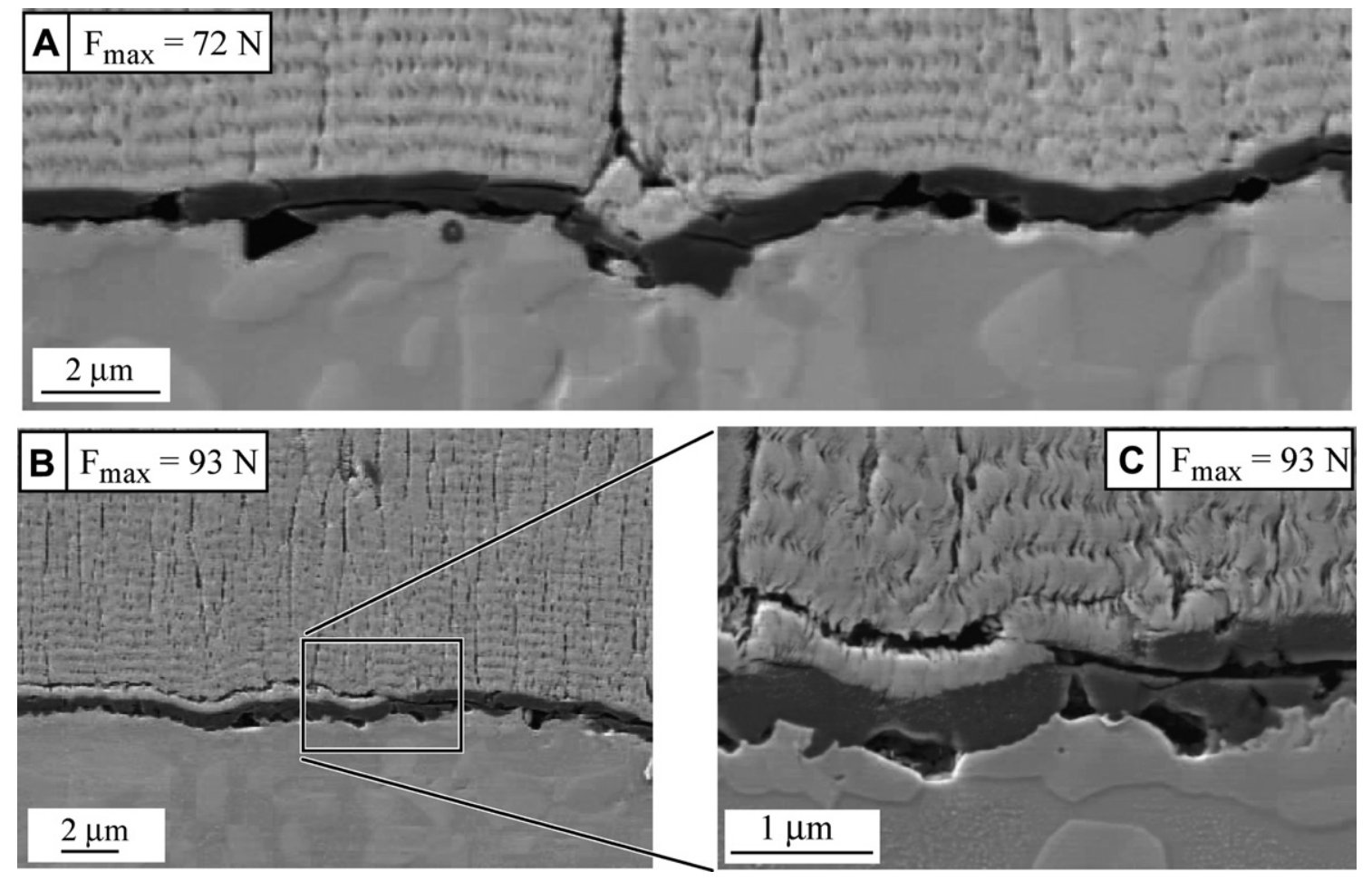

Fig. 11. Crack paths observed in as-coated specimens: (A) crack propagation along the interface between bond coat and TGO facilitated by pores, and within the TGO (indentation force: $72 \mathrm{~N}$, near to the right end of the crack at about $350 \mu \mathrm{m}$ from the indentation center); (B, C) crack propagation within the top coat between sublayers (formed during processing due to the rotation of the specimen in the ceramic vapor cloud), and change of crack path into the TGO (indentation force; $93 \mathrm{~N}$, right end of the crack at about $300 \mu \mathrm{m}$ from the indent center).

ally connected with the annular cracks. The length and path of the debonding cracks and shear bands appear to depend on the time-at-temperature:

- For the same maximum indentation force, the diameter of the annular cracks is smaller in thermally aged than in as-coated systems. Associating this crack diameter with the (apparent) interfacial fracture toughness of the TBC system results in the aged coatings having higher interfacial fracture toughness than the as-coated material. This is in contradiction to the typically observed behavior of TBCs in thermal and thermomechanical tests and in service $[23,25,26]$. Careful examination of the crack pattern of indentation-induced crack systems revealed that the crack paths changed due to aging. These changes in crack pattern can be associated with changes in morphology, stiffness, strength and fracture resistance of the ceramic top coat due to sintering and to the growth of the TGO.

- The conical shear bands that typically originated near the contact area between the indenter and top coat were more expressed and straight in the as-coated specimens than in the aged ones. In aged condition, the shear bands kinks further away from the interface between the top coat and the bond coat. The microstructure of the top coat evolves with time-at-temperature due to sintering, which leads to an increase in both the strength and the stiffness of the top coat (e.g. [27]). Consequently, as the top coat is aged, more energy is absorbed by the top coat during indentation, leaving less work to be used to drive a interfacial crack parallel to the interface between the top and bond coat.

An important observation is also made at the interface between the top and the bond coat: Indentation testing appears not to generate failure in the true weakest interface. For aged samples, the annular delamination cracks do not penetrate the dense layer of the newly formed TGO, and are either propagating in the ceramic top coat, in the porous mixed zone of the TGO, or in the interface between the mixed zone and the dense TGO (Fig. 13). However, in thermal and thermomechanical long-term testing, the failure occurs typically at the interface between TGO and bond coat, which implies that this interface is the weakest interface in thermally exposed TBCs (for the class of TBCs investigated). This is also supported by our observation of spontaneous and delayed separations of the ceramic coating where the separation occurred at the interface between the bond coat and TGO. Spontaneous separation occurred for samples aged for $400 \mathrm{~h}$, directly after removing them from the furnace. Delayed separation occurred at a significant time after the indentation was conducted for the specimens aged for $200 \mathrm{~h}$ (these types of delayed spallations are sometimes referred to as the "desk-top effect" and are associated with stress corrosion cracking [28]). Interestingly, both the spontaneous and 

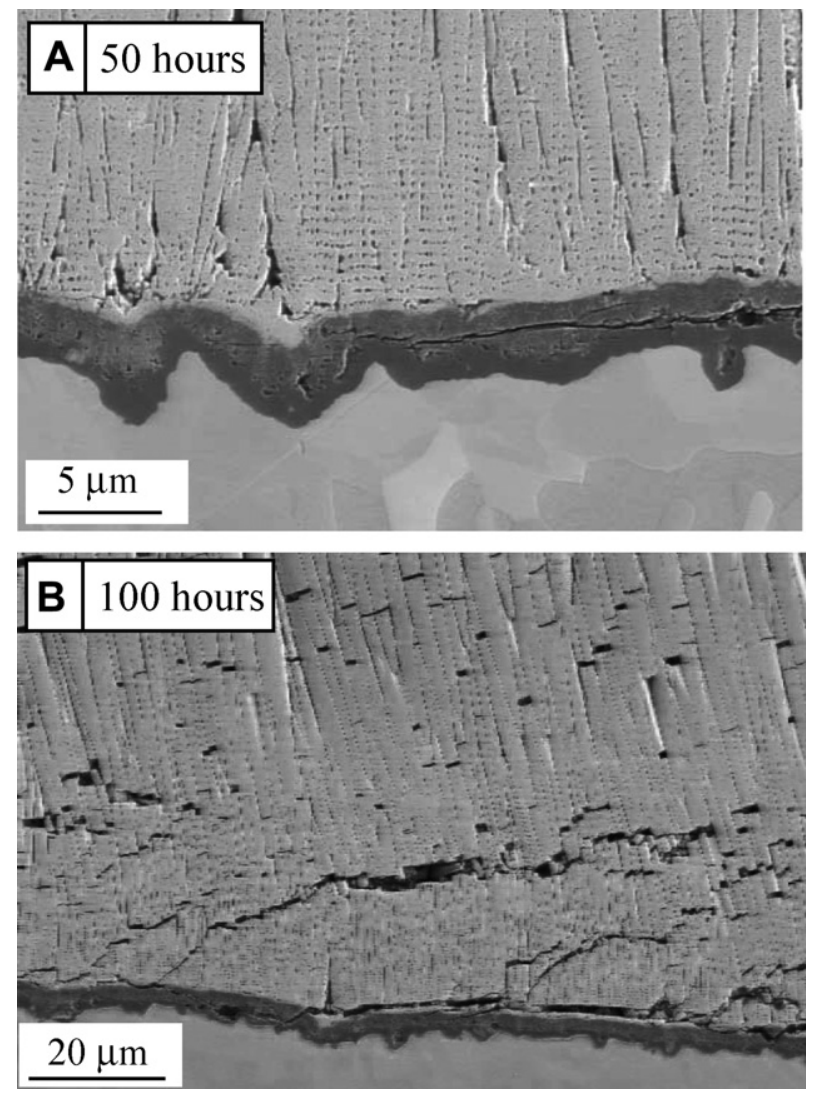

Fig. 12. Crack paths in thermally aged specimens: (A) after $50 \mathrm{~h}$ at $1000{ }^{\circ} \mathrm{C}$ in air after indentation with a load $559 \mathrm{~N}$, left end of debonding crack; (B) after $100 \mathrm{~h}$ at $1000{ }^{\circ} \mathrm{C}$ in air after indentation with a load of $610 \mathrm{~N}, 500 \mu \mathrm{m}$ left from indent center.

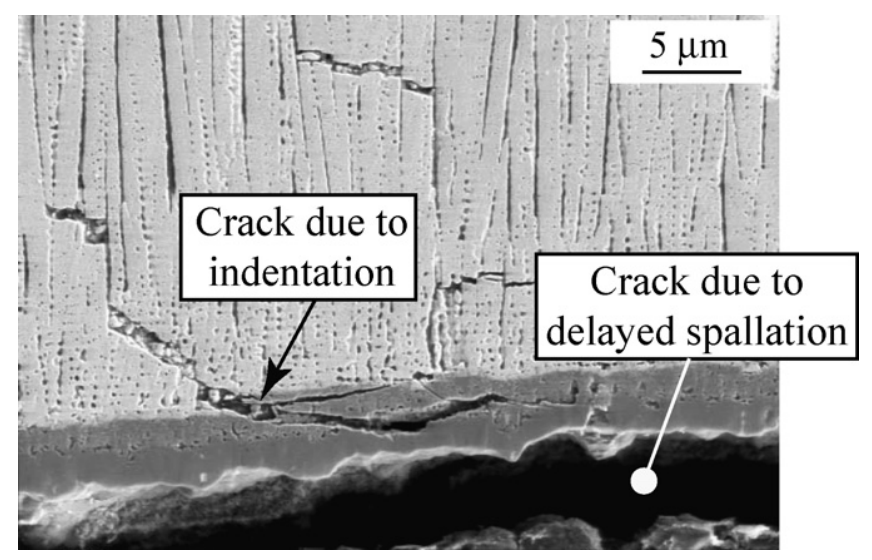

Fig. 13. Typical crack pattern in a sample aged for $200 \mathrm{~h}$ at $1000^{\circ} \mathrm{C}$. Crack induced due to indentation force of $60 \mathrm{~N}$ extends into the porous TGO and in the interface between porous and dense TGO. The larger crack is due to a spontaneous crack, induced due to delayed spallation ("desktop effect").

the delayed separation of the ceramic layers from the substrate were not induced by the indentation crack system but by stress concentrations at the free edges of the layered system with the separation between TGO and BC. Fig. 13 displays the cross-section of a $200 \mathrm{~h}$ aged specimen showing a crack induced by indentation (indentation force $60 \mathrm{~N}$ ) and a crack induced by the spontaneous (delayed) failure. The crack induced by indentation is "trapped" at the porous line between the intermixed and dense layer of the TGO, whereas the top coat and the entire TGO is separated from the bond coat due to the delayed, spontaneous separation. We interpret these results as meaning that the true weakest path of the system is between the TGO and the bond coat. Thus, the strain energy field driving the crack induced by indentation appears not to be able to propagate the crack into the interface which corresponds to the true weakest path.

For higher indentation loads, the substrate and the bond coat deform plastically due to the indentation (Fig. 8). Evidently, some of the energy imposed during the indentation will be absorbed by this deformation, and must be carefully included when evaluating the indentation results.

In summary, it appears that the delamination cracks induced by the indentation do not necessarily represent the most likely path of delamination failure, and that a significant amount of energy imposed on the system during indentation is absorbed by the top coat. Thus, care must be taken when using indentation techniques to establish interfacial fracture toughness when the coating cannot be treated as "thin" compared to the indentation. In the companion paper to this study, numerical simulations to increase the understanding of indenting $\mathrm{TBC}$ systems are conducted [16] .

\section{Concluding remarks}

The possibility of using Rockwell indentation to establish the interfacial fracture toughness in TBCs has been investigated. Indentations normal to the coating surface were conducted on specimens that were in "as-coated" conditions and specimens that had been exposed for various lengths of time in air at $1000{ }^{\circ} \mathrm{C}$. By measuring the size of the annular debonding cracks, we found that: (i) the as-coated samples resulted in larger debonding cracks than the aged samples; and (ii) the crack response could be divided into two regions: one response for "low" maximum indentation force and another for "high" maximum indentation force. The latter is the main focus of a companion paper [16]. The first observation could be interpreted as the aged samples having more resistance to failure than the as-coated, which is at variance to the current understanding of TBCs, and is investigated in this paper as well as in a companion paper [16].

From careful microscopy, it was found that the formation and size of the debonding cracks are controlled by the deformation of the brittle top coat (YSZ), the morphology and strength of the TGO $\left(\mathrm{Al}_{2} \mathrm{O}_{3}\right)$, and for higher indentation loads the deformation of the substrate. Extensive deformation of the top coat in terms of crushing and the formation of conical shear bands were observed. Since the properties of the top coat evolve with time due to sintering, not only the change in elastic properties but also 
- and more importantly - the strength of the top coat must be considered when evaluating the interfacial fracture toughness.

In thermally aged specimens, the dense TGO inhibited the propagation of indentation-induced cracks into the interface between the bond coat and the TGO, which is known from service experience to be the weakest interface for this class of coatings. (The spontaneous and the delayed delaminations observed for the specimens subjected to the highest time-at-temperature occurred at the interface between the TGO and the bond coat, supporting this assertion.) However, the cracks induced by the indentation of the top coat propagate at the interface between the TGO and top coat, and within the TGO. Thus, the stress field induced by indentation in combination with the strength of the dense TGO did not create an opportunity for the overall weakest interface to fail in the aged samples.

In addition, for the largest indentation loads, the bond coat and the substrate deform plastically. Thus, it is possible that using indentation testing for establishing interfacial fracture toughness of TBCs can only be conducted on substrates (and bond coats) with high yield strength.

These results together imply that it is important to know the limitations of the Rockwell Brale C indentation test for estimating the interfacial fracture toughness of multilayered structures and to evaluate the results carefully, including the microstructural behavior, during the indentation.

\section{Acknowledgments}

The authors acknowledge the financial support by the National Science Foundation (DMR-0346664) and the European Community's Human Potential Program under contract HPRN-CT-2002-00203 [SICMAC]. We would also like to thank Dr. Iulian Mircea for help in performing the indentation experiments.

\section{References}

[1] Evans AG, Mumm DR, Hutchinson JW, Meier GH, Petit FS. Progr Mater Sci 2001;46:505.
[2] Padture NP, Gell M, Jordan EH. Science 2002;296:280.

[3] Darzens S, Karlsson AM. Surf Coat Technol 2004;177-178C:108.

[4] Shaw LL, Barber B, Jordan EH, Gell M. Scripta Mater 1998;39:1427.

[5] Vasinonta A, Beuth JL. Eng Fracture Mech 2001;68:843.

[6] Ruud JA, Bartz A, Borom MP, Johnson CA. J Am Ceram Soc 2001;84:1545.

[7] Aktaa J, Sfar K, Munz D. Acta Mater 2005;53:4399.

[8] Bartsch M, Baufeld B. In: Proceedings of the European conference on fracture, vol. I. ECF 14; 2002. p. 209.

[9] Guo SQ, Mumm DR, Karlsson AM, Kagawa Y. Scripta Mater 2005;53:1043.

[10] Bahr HA, Balke H, Fett T, Hofinger I, Kirchhoff G, Munz D, et al. Mater Sci Eng A 2003;362:2.

[11] Ma Q. Ph.D. thesis. Carnegie Mellon University, Pittsburgh; 2004.

[12] Begley MR, Mumm DR, Evans AG, Hutchinson JW. Acta Mater 2000;48:3211.

[13] Bartsch M, Mircea I, Suffner J, Baufeld B. Key Eng Mater 2005;290:183.

[14] Drory MD, Hutchinson JW. Proc. R. Soc. Lond. 1996;A452:2319.

[15] Mircea I, Bartsch M. Modified indentation test to estimate the interfacial fracture toughness of thick thermal barrier coating systems. In: Proceedings of the 11th international conference on fracture-ICF, Turin, vol. 11. 2005. p. 20.

[16] Yan J, Karlsson AM, Bartsch M, Chen X [submitted for publication]

[17] Lughi V, Tolpygo VK, Clarke DR. Mater Sci Eng A 2004;368:212.

[18] Renteria AF, Saruhan B. J Eur Ceram Soc 2006;26:2249.

[19] Schulz U, Menzebach M, Leyens C, Yang YQ. Surf Coat Technol 2001;146:117.

[20] Watanabe M, Mercer C, Levi CG, Evans AG. Acta Mater 2004;52:1479.

[21] Chen X. Mech Mater 2005;37:447.

[22] Evans AG, Fleck NA, Faulhaber S, Vermaak N, Maloney M, Darolia R. Wear 2006;260:886.

[23] Sohn YH, Jayaraj B, Laxman S, Franke B, Karlsson AM. J Mater (JOM) 2004;56:53

[24] Handoko RA, Beuth JL, Meier GH, Pettit FS, Stiger MJ. Key Eng Mater 2001;197:165.

[25] Wright P. Mater Sci Eng A 1998;245:191.

[26] Bartsch M, Baufeld B, Dalkilic S, Chernova L, Heinzelmann M. Int J Fatigue 2008;30:211.

[27] Bartsch M, Fuchs U, Xu J. In: Proceedings of the 31st international conference and exposition on advanced ceramics and composites; 2007. p. 11.

[28] Sergo V, Clarke DR. J Am Ceram Soc 1998;81:3237. 